\title{
The first glycosides with pyrazolo[3,4-c]isoquinoline aglycone moiety. Synthesis and NMR structure investigation
}

\author{
Natalia Bogdan $^{1}$, Serge Bogza ${ }^{1}$, Dalila Bousta ${ }^{2}$, Tatiana Chupakhina ${ }^{3}$, Andriy Grafov ${ }^{4}$, Olena Holembiovska ${ }^{1}$, \\ Andrii Khairulin $^{1}$, Volodymyr Kyrianov ${ }^{3}$, Serhii Suikov ${ }^{1}$ \\ ${ }^{1}$ Institute of Organic Chemistry of National Academy of Sciences of Ukraine, 5, Murmanska St., 02660 Kyiv, \\ Ukraine; bogza@i.ua \\ ${ }^{2}$ Faculty Of Science, University Sidi Mohamed Ben Abdellah, Dhar El Mahraz, Fes, Morocco \\ ${ }^{3}$ V.I.Vernadsky Taurida National University \\ ${ }^{4}$ Laboratory of Inorganic Chemistry, University of Helsinki, FI
}

\begin{abstract}
The synthetic potential of polyfunctional derivatives of a condensed system of pyrazolo[3,4- $c$ ] isoquinoline has been investigated. For the first time a series of derivatives with a fragment of glucosamine was obtained and their spectral properties is described.
\end{abstract}

Keywords: pyrazolo[3,4-c]isoquinolines, glycosylation, correlation spectroscopy, N,O-glucosides, oxazoline.

\section{Introduction}

Isoquinolines condensed with the azoles and other heterocycles on the " $c$ " margin have recently become popular targets of medicinal chemistry. Based on the modified Pictet-Spengler reaction we developed a convenient method of preparing pyrazolo[3,4-c]isoquinolines $\mathbf{I}[1,2]$ which have become hit-leaders in the search for new inhibitors of kinase anaplastic lymphoma [3-5]. They also increase the effectiveness of chemotherapy drugs and antibiotics, contribute to detoxication of cells and tissues, regulate multidrug transport systems across the blood brain barrier [6,7]. The distinctive property of pyrazolo[3,4-c]isoquinolines is low toxicity [5]. Pyrrolo [3,4-c]isoquinoline-2,5-diones II [8,9] are inhibitors of glycogen synthase kinase 3 (GSK 3) and activators of Wnt signaling pathway [10] which is important for cell proliferation, differentiation, and apoptosis. Pyrrolo[3,4- $c$ ]- $\beta$ carboline-1,3-dienes III [8] have been studied as a new class of inhibitors of tyrosine kinases [11]. Thieno [3,4-c]isoquinoline IV, synthesis of which we carried out several years ago for the first time [9], have been studied as promising inhibitors NFkappaB receptor [12,13]. Therefore, the probability of new medicinal substances with the structure of condensed isoquinolines is very high, and the development of alternative methods of synthesis and functionalization azolo- and other condensed isoquinolines seems relevant, especially for medicinal chemistry.<smiles>[R]c1n[nH]c2nc([Al])c3cc(OC)c(OC)cc3c12</smiles>

I<smiles>[R]c1nc2c(c3cc(OC)c(OC)cc13)C(=O)NC2=O</smiles>

II<smiles>O=C1NC(=O)c2c1nc([AlH2])c1[nH]c3ccccc3c21</smiles>

III<smiles>[R]c1nc2csc([R])c2c2cc(OC)c(OC)cc12</smiles>

IV

However, it is a long way from the substance with a specific activity to the drug, "from the flask to the bedside". For heterocyclic systems I-IV a serious limitation is their low solubility, and, accordingly, bioavailability. Glycosylation is one of the perspective ways of modifying the molecule properties, including the solubility improvement. It is well illustrated by the example of the existing anticancer and antiviral drugs, such as Zidovudine, Emtricitabine, Cytarabine, Azacitidine, etc. Thus, the synthesis of new glycosides containing a pyrazolo[3,4-c]isoquinoline as aglycone moiety and NMR studies of their structure were the aim of this work. 


\section{Results and discussion}

The structure of pyrazolo[3,4-c]isoquinolines 2-5 has two reactive sites which may react with 2-acetamido-2deoxy-alpha-D-glucopyranosyl chloride 3,4,6-triacetate, a phenolic hydroxyl group in the 5-position substituent and non substituent nitrogen atom N (3) of the pyrazole moiety of the molecule. Glucosaminides 6-9 were obtained by the interaction of pyrazolo[3,4-c]isoquinolines 2-5 with $\alpha$-D-glucosaminyl chloride 1 under phase transfer catalysis reaction [14,15]. Glucosaminides 6-9 were obtained in yields of 49-66\%. It was found that in the reaction of pyrazolo[3,4-c]isoquinoline 5 with 2-acetamido-2-deoxy-alpha-D-glucopyranosyl chloride 3,4,6triacetate only one of two possible regioisomers $\mathbf{9}$ was obtained. The nitrogen atom of the pyrazole ring did not interact with 2-acetamido-2-deoxy-alpha-D-glucopyranosyl chloride 3,4,6-triacetate under the conditions used in the reaction.

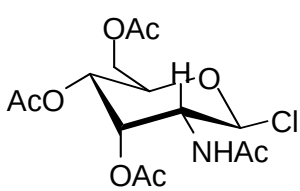<smiles>[R]c1cc(-c2nc3c([R])nn([R])c3c3cc(OC)c(OC)cc23)ccc1O</smiles>

$2-5$
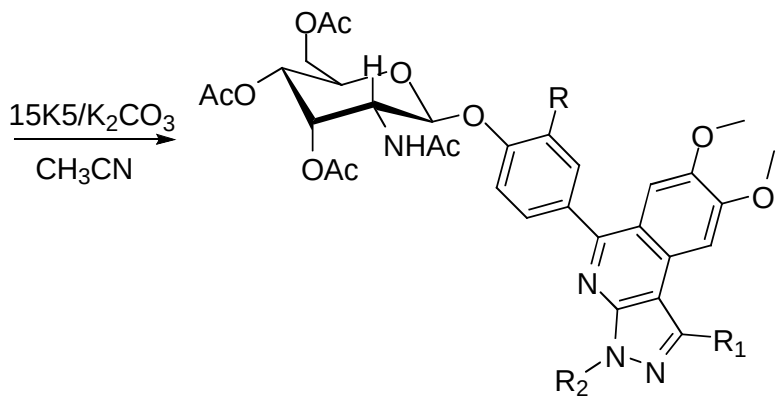

6-9

$$
\begin{aligned}
& \text { 2, 6: R }=H, R_{1}=M e, R_{2}=P h \\
& \text { 3, 7: R }=O M e, R_{1}=E t, R_{2}=P h \\
& \text { 4, 8: R }=H, R_{1}=E t, R_{2}=P h \\
& \text { 5, 9: R }=H, R_{1}=M e, R_{2}=H
\end{aligned}
$$

Attempt to synthesize $\mathrm{N}$-glycoside from compound $\mathbf{1 0}$ under phase transfer catalysis (PTC) was unsuccessful. Therefore, the method described in the article [16] has been used. We obtained glucosaminide $\mathbf{1 1}$ by heating 2acetamido-2-deoxy-alpha-D-glucopyranosyl chloride 3,4,6-triacetate $\mathbf{1}$ with pyrazolo[3,4-c]isoquinoline $\mathbf{1 0}$ in the presence of excess mercury (II) bromide in toluene. Low yield of the desired product (18\%) caused stringent conditions of synthesis, which have lead to partial thermal degradation of carbohydrates in the reaction mixture and formation of the oxazoline $\mathbf{1 2}$.

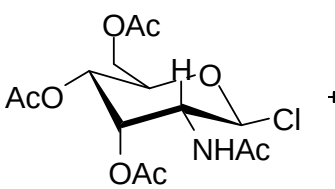

1

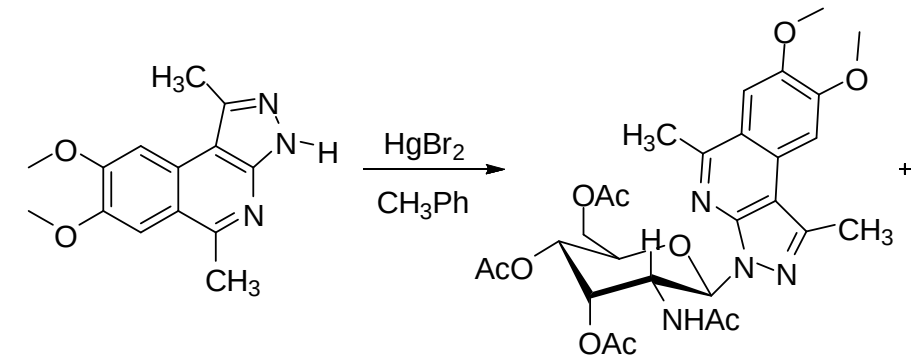

10

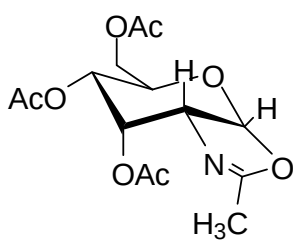

12

To identify the structure of the obtained compounds the combination of $1 \mathrm{D}$ and $2 \mathrm{D}{ }^{1} \mathrm{H}$ NMR spectroscopy was used. The ${ }^{1} \mathrm{H}$ NMR spectrum of 4-(1-ethyl-7,8-dimethoxy-3-phenyl-3H-pyrazolo [3,4-c] isoquinolin-5-yl) phenyl 3,4,6-tri-O-acetyl-2-(acetylamino)-2-deoxy-hexapyranozide 8 does not contradict the proposed structure but due to overlapping signals a number of them cannot be identified by the 1D spectrum. However, normalization of the integral intensities of the signals belongs to different parts of the molecule, the ratio between them is integral and of the respective expected structure. 


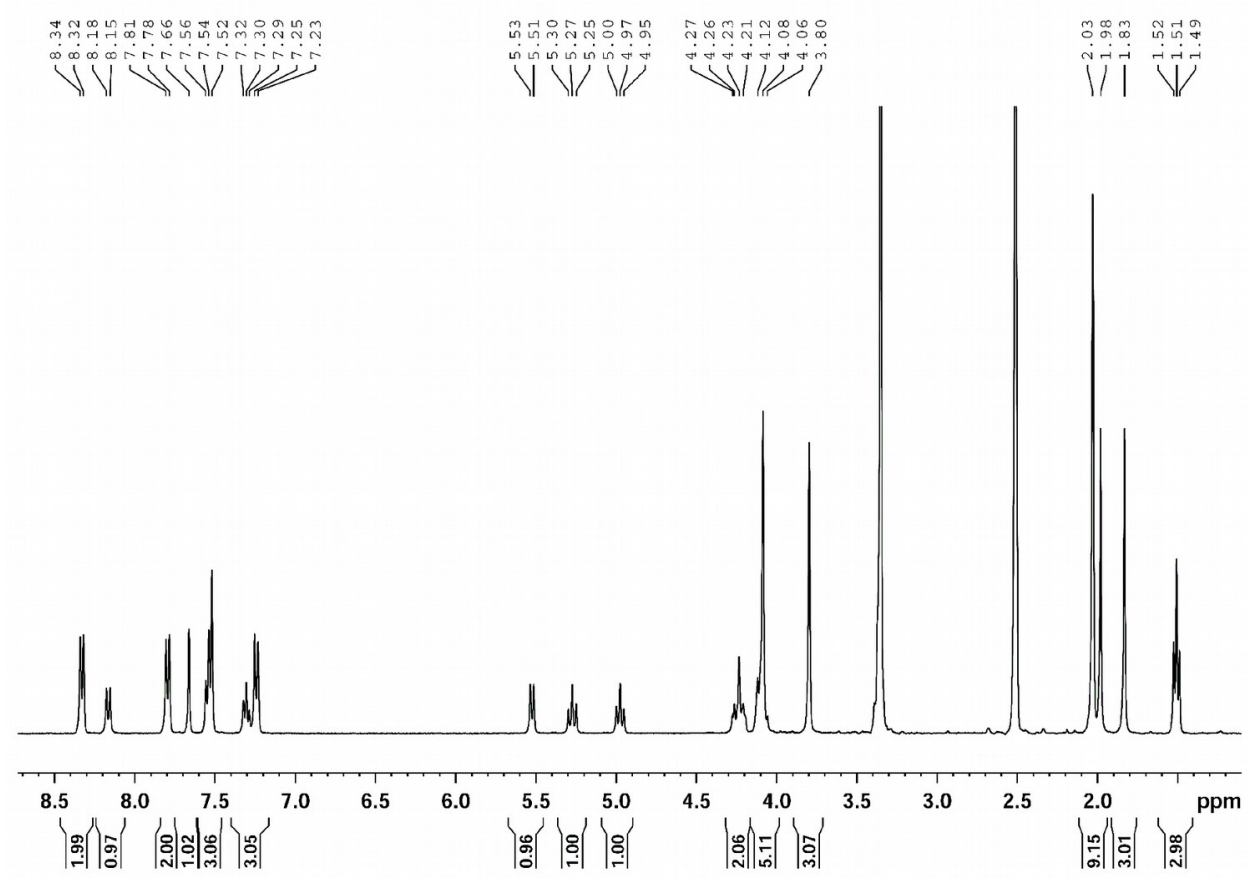

Fig 1. ${ }^{1} \mathrm{H}$ NMR spectrum of 4-(1-ethyl-7,8-dimethoxy-3-phenyl-3H-pyrazolo [3,4-c] isoquinolin-5-yl) phenyl 3,4,6-tri-Oacetyl-2-(acetylamino)-2-deoxy-hexapyranozide 8

It is not possible to identify doublets relating to para-substituted phenylene ring against the background of doublets of monosubstituted phenyl system without additional information in the area of aromatic protons (8.4-7.2 ppm multiplet system). Furthermore, the absence of the quartet of ethyl group in the aliphatic region in $1 \mathrm{M}$ spectrum should be noted. We used the technique of 2D COSY GP (Bruker) with PGF. The spectrum was obtained using the default settings. A relatively broad lines of the least rapidly relaxing methyl groups allowed to rely on the absence of an appreciable contribution of T1 noise.

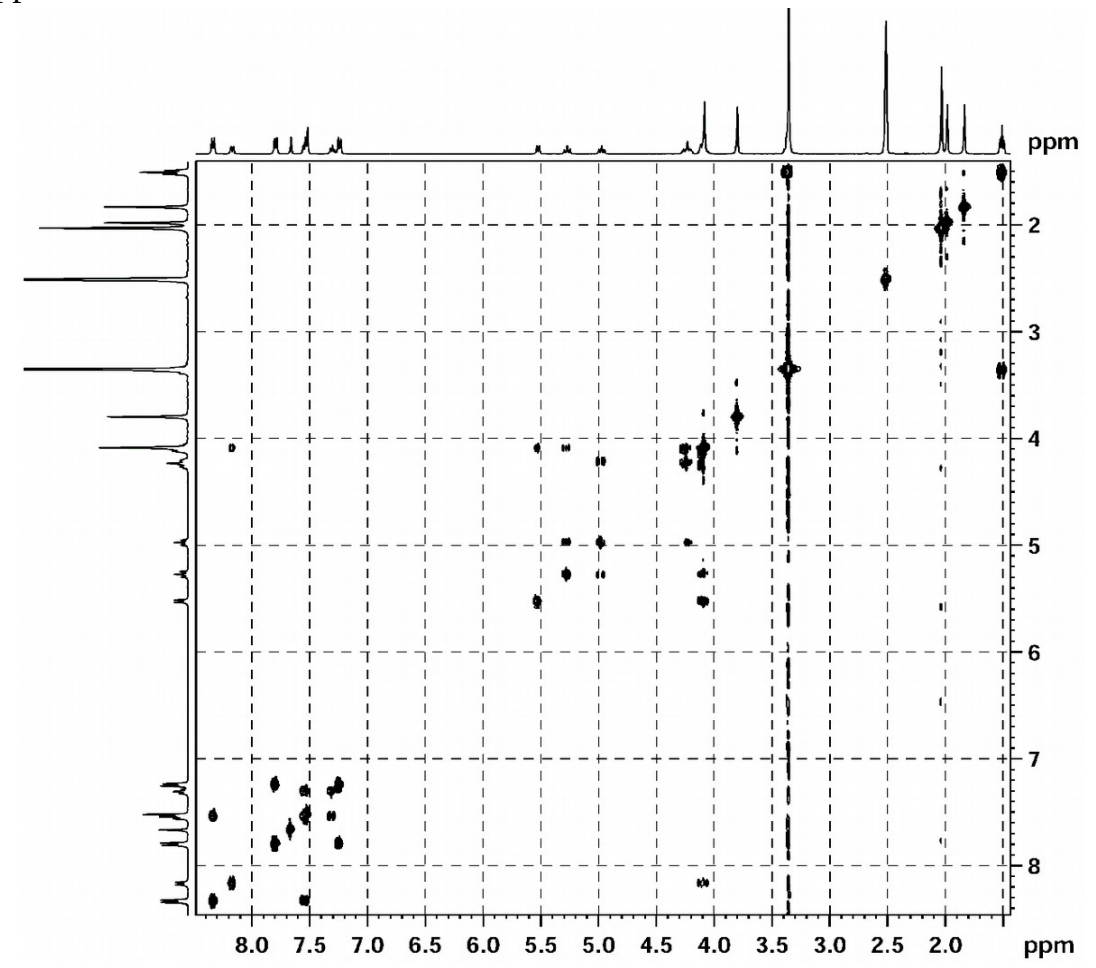

Fig.2 2M 1H COSY NMR spectrum of the glycoside 8

Evident approach to the analysis of COSY spectra is the "unwinding" of the topological network of the spin system of simply connected site atom. The signal of the only $\mathrm{NH}$ group is a doublet at $8.16 \mathrm{ppm}(1 \mathrm{H},=7.0$ 
$\mathrm{Hz}$ coupling constant) is one of the most advantageous starts in this molecule. This signal shows a cross-peak with multiplet at 4.15-4.00 ppm partially overlapping with the singlet of one methyl group, and even with one proton of glycoside fragment.

Cross-peak with the multiplet system $(5 \mathrm{H})$ at $4.15-4.00 \mathrm{ppm}$ indicates the position of proton at $\mathrm{C}_{2}$ associated with it. Proton d $1 \mathrm{H}$ signal at $5.52 \mathrm{ppm}$ is linked (cross-peak) with this same proton by a single structure splitting of which may correspond to the proton at $C_{1}$. Thus, the position of the proton signals at $C_{1}$ and $C_{2}$ is exactly determined, and it belongs to the $\mathrm{NH}$ group of acetylamino pyranozide residue. The integrated intensity of the multiplet at $4.15-4.00 \mathrm{ppm}, 5 \mathrm{H}, 3 \mathrm{H}$ of them occur at $\mathrm{CH}_{3}$ group, $1 \mathrm{H}$ at $\mathrm{C}_{2}$ proton. To classify the remaining proton, the additional analysis was performed. Triplet $1 \mathrm{H}$ at $5.27 \mathrm{ppm}$ has a cross-peak with a signal referred above to the proton at $\mathrm{C}_{2}$. Thus, this is a proton at $\mathrm{C}_{3}$ position. Signal form is a triplet which corresponds to the nearest environment of the two protons at $\mathrm{C}_{2}$ and $\mathrm{C}_{4}$. This triplet has a strong cross-peak with a triplet $1 \mathrm{H}$ at 4.97 ppm corresponding to proton at $\mathrm{C} 4$. The signal at 4.97 shows a cross-peak in the component of multiplet $2 \mathrm{H}$ at 4.3-4.2 ppm which demonstrates the relationship with the $\mathrm{C}_{5}$. The two remaining non-equivalent protons of anomeric atom $\mathrm{C}_{6}$ are presented by multplets of $1 \mathrm{H}$ in the range of 4.30-4.2 and 4.15-4.00 ppm which corresponds to the fine pattern of interactions in this area in COSY spectrum. Thus, previously unidentified $1 \mathrm{H}$ in this multiplet is a signal which belongs to one of the $\mathrm{C}_{6}$ protons. $3 \mathrm{H}$ triplet at $1.51 \mathrm{ppm}$ belongs to ethyl group in position 1 , as well as its only neighbor, obviously, quartet, being on signal $3.45 \mathrm{ppm}$ of water. Four $3 \mathrm{H}$ singlets at 4.21, 3.80, 1.98 and 1.83 are signals of the three methyl groups of the acetyl and one acetamino substituents in hex pyranozide cycle. Field of aromatic protons is attributable likewise. So, it is easy to stand out protons of parasubstituted phenylene rings, two doublets for $2 \mathrm{H}$ at 7.24 and $7.80 \mathrm{ppm}$, demonstrating the cross-peak at COSY only among themselves. The system of lines $(\mathrm{d}, 2 \mathrm{H}, 8.33)-(\mathrm{t}, 2 \mathrm{H}, 7.54)-(7.30 \mathrm{ppm} \mathrm{t} 1 \mathrm{H})$ is mono substituted phenyl substituent at the 3-position. The two are isolated by $1 \mathrm{H}$ singlet at 7.52 and $7.66 \mathrm{ppm}$, corresponding the protons in positions 6 and 9. The spectral pattern of the other compounds is as discussed above. The significant difference in the spectrum of glycoside 9 is a signal (N3) $-\mathrm{H}$ of pyrazole nucleus is $1 \mathrm{H}$ singlet at $13.29 \mathrm{ppm}$. Signal of NH of acetylamino group is located at $8.16 \mathrm{ppm}(\mathrm{d}, 1 \mathrm{H})$ and has a coupling constant $8.9 \mathrm{~Hz}$.

The spectrum of $\mathbf{N}$-glycoside $\mathbf{1 1}$ with glycoside moiety at the pyrazole nitrogen atom has noticeable differences. The signal at $\mathrm{C}_{1}$ and up to $4.8(+0.3 \mathrm{ppm})$ signal at $\mathrm{C}_{5}$ of glycoside residue significantly broadened and shifted in a weak field, up to $6.49 \mathrm{ppm}(+1.0 \mathrm{ppm})$. The signals of protons at $\mathrm{C}_{3}$ and $\mathrm{C}_{4}$ are also shifted downfield retaining their characteristic symmetry which increased difference in chemical shifts of protons of the exocyclic $\mathrm{CH}_{2}$ group up to $0.3 \mathrm{ppm}$.

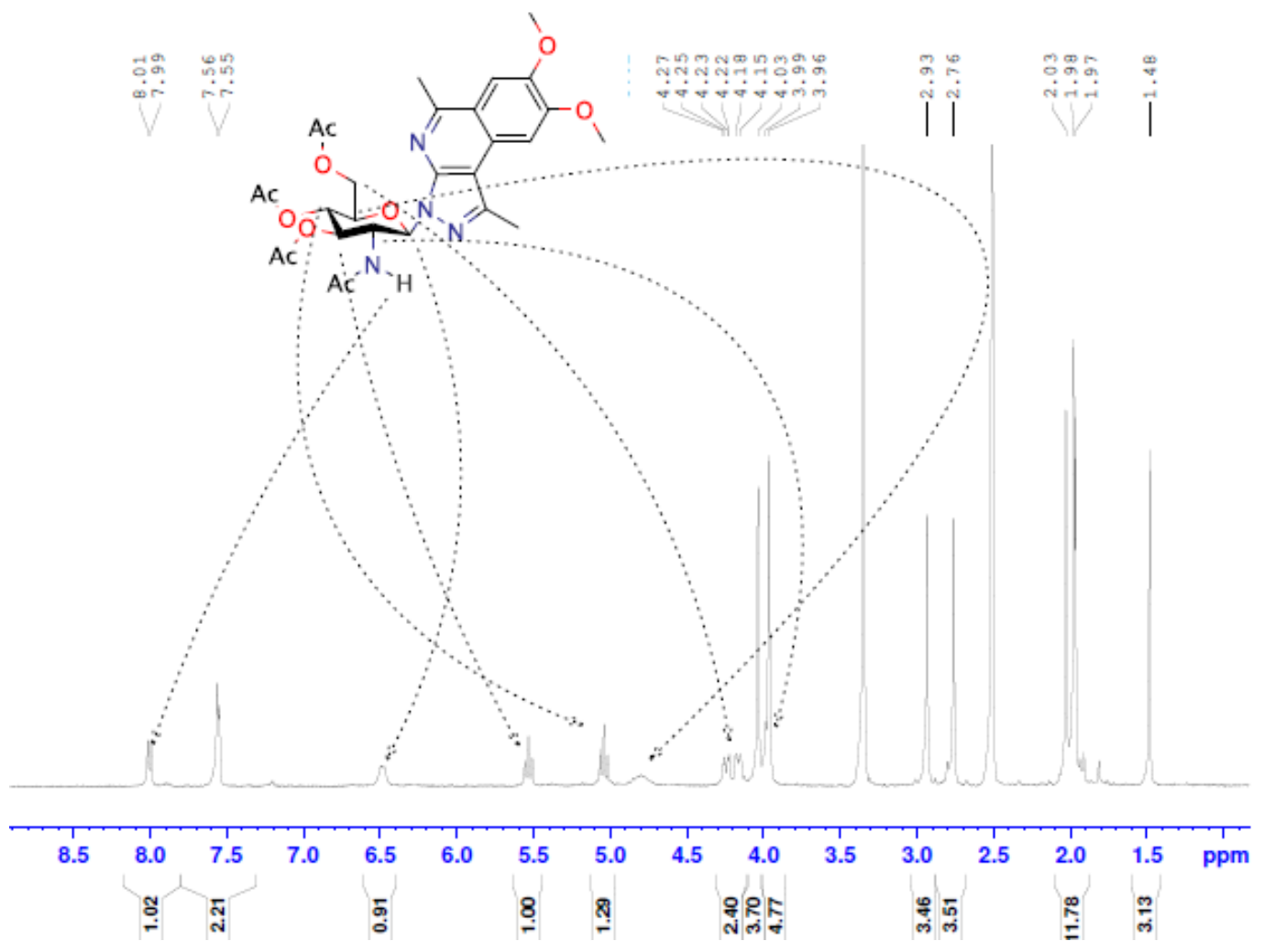


Fig.3. ${ }^{1} \mathrm{H}$ NMR spectrum of 1,5-dimethyl-3-(2-acetamido-3,4,6-tri-O-acetyl-2-deoxy- $\beta$-D-glucopyranosyl oxy)-7,8dimetoxypirazolo [3,4-c] isoquinoline 11.

A number of signals of glycoside residues which demonstrated high intramolecular mobility in previous compounds, in this case, significantly extended due to the exchange between the sterically caused conformers. This effect most impacts protons at $\mathrm{C}_{1}$ and $\mathrm{C}_{5}$ nuclei of carbohydrate residue that logically linked to the influence of heterocyclic fragment. Relaxation time of signals series is so small that in the 2D COSY spectra they do not demonstrate cross-peaks expected for their molecular structure (spin system has time to cool during the incremental pause of pulse sequence).

Features of distribution of magnetic anisotropy zone at the pyrazoloisoquinoline nucleus has not yet been studied. Our early results $[2,17]$ show that the fragments are in an orthogonal plane to pyrazole cycle typical downfield shift. However, for aromatic substituents in the 3-position of the heterocyclic system such significant inhibition of intramolecular movements was not observed. Comparing stability of the signals position in Figure 4 shows the aliphatic region of the spectra of all received glycosides.

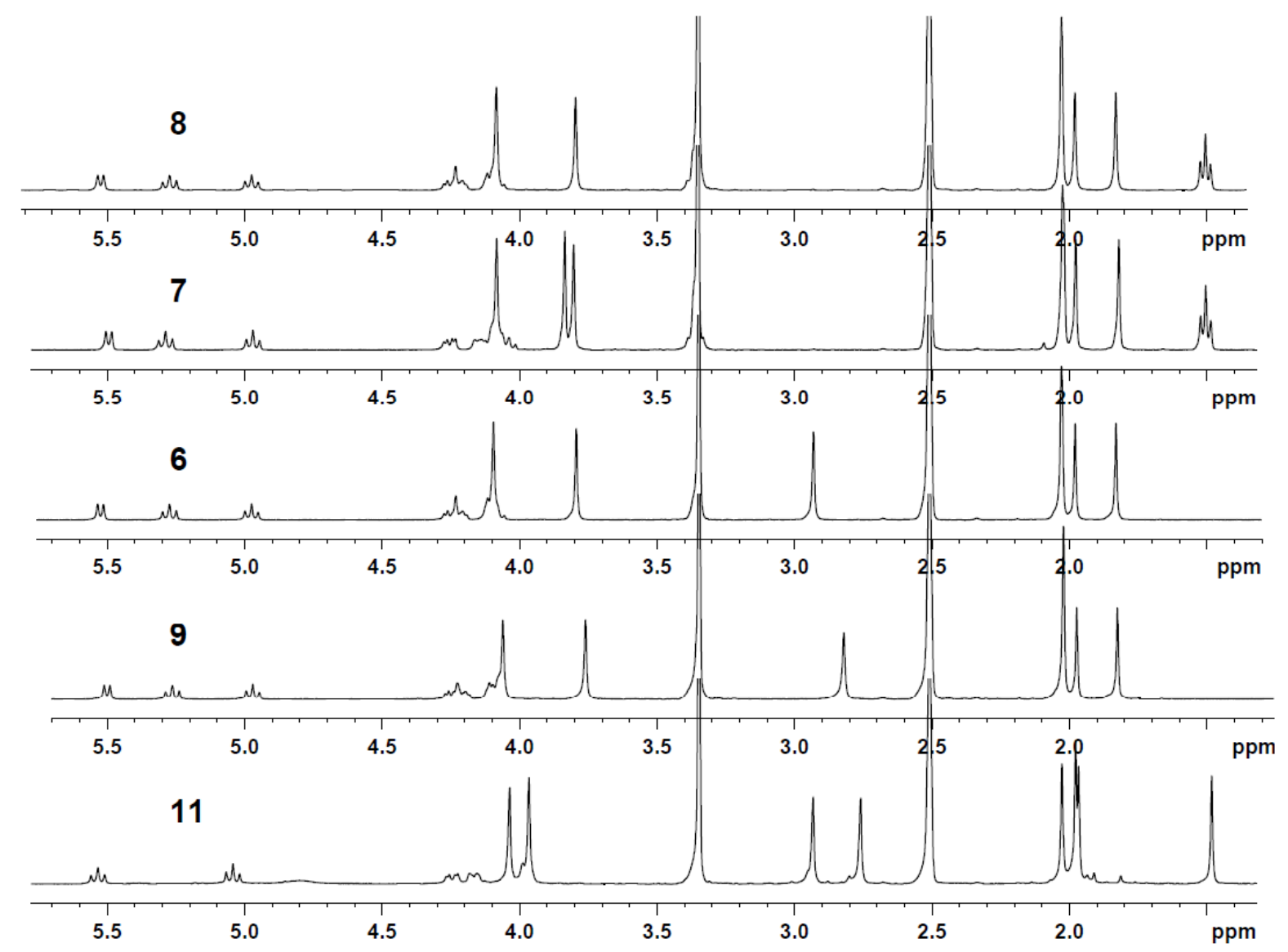

Fig. 4. Comparison of aliphatic areas ${ }^{1} \mathrm{H}$ NMR spectra of compounds $\mathbf{6 , 7 , 8 , 9 , 1 1}$ reviewed in the article.

\section{Conclusions}

To sum it up, we describe the methods of obtaining N- and O-glycosides with the pyrazolo[3,4-c]isoquinoline as aglycone moiety. O-glycosides are obtained in good yields under phase transfer catalysis. Mercury (II) bromide is used for glycosylation of nitrogen atom at pyrazole ring. NMR study of the structure has shown high stability of the glycoside residue proton signals. Studies of the biological activity of the compounds is underway and will be presented in due course.

Publication are based on the research provided by the grant support of the State Fund For Fundamental Research (project No 20156). 


\section{Experimental}

${ }^{1} \mathrm{H}$ spectra were recorded with a Bruker AVANCE $400 \mathrm{MHz}$ spectrometer at $400.16 \mathrm{MHz}$ in solutions DMSO-d6. Chemical shifts $(\delta)$ in ppm are reported by using TMS as internal standard. The coupling constants (J) are given in Hertz. Melting points were measured on PTP capillary melting point apparatus. Optical rotations were measured at $20-22{ }^{\circ} \mathrm{C}$ on a Polamat-A polarimeter. Column chromatography was carried out using Kieselgel silica gel 60, 0.063-0.2 mm (Merck). TLC was carried out on silica gel plates (Merck). Visualisation was achieved by UV (254) or $5 \%$ solution of $\mathrm{H}_{2} \mathrm{SO}_{4}$ in butanole-1 staining.

\section{General procedures for synthesis of compound 6-9}

A mixture of appropriate isoquinoline $\mathbf{2 - 5}(1.4 \mathrm{mmol}), \alpha$-chloride $\mathbf{1}(1.4 \mathrm{mmol})$, anhydrous potassium carbonate $(6.3 \mathrm{mmol})$ and 15 -crown-5 $(0.28 \mathrm{mmol})$ in dry acetonitrile were maintained at $20-22{ }^{\circ} \mathrm{C}$ temperature to full convertion of glycosyl-donor (TLC control). The solid phase was filtered off, washed by dry acetonitrile ( $2 \times 5$ $\mathrm{ml}$ ) solvent was evaporated in vacuo. The residue was purified by column chromatography [silica gel, $\mathrm{CHCl}_{3} / \mathrm{PrOH}(100: 1) \rightarrow \mathrm{CHCl}_{3} / \mathrm{iPrOH}(30: 1)$, to give target products 6-9.

1-Methyl-3-phenyl-5-[4-(2-acetamido-3,4,6-tris-O-acetyl-2-desoxy- $\alpha$-D-glycopyranosyloxy)phenyl]-7,8dimethoxypyrazolo[3,4-c]isoquinoline (6), yield $66 \%$; m.p. $274^{\circ} \mathrm{C}$, $[\alpha]_{546}-25^{\circ}$ (c 1,0; chloroform). ${ }^{1} \mathrm{H}$ NMR: d. 2H 8.32 ppm J=8.3 Hz; d. 1H 8.16 ppm, J=8.9 Hz; d. 2H 7.79 ppm, J=8.50 Hz; s. 1H 7.72 ppm, dd 2H 7.53 ppm J=8.3 Hz, J=7.4 Hz; s 1 H 7.51 ppm; t 1H 7.30 ppm, J=7.4 Hz; d. 2H, 7.24 ppm, J=8.50 Hz; d. 1H 5.52 ppm J=8.3 Hz, dd 1H 5.27 ppm J=9.7 J=9.8 Hz; dd 1H 4.97 ppm J=9.3 J=9.5 Hz; m 2H 4.30-4.15 ppm; m 5H 4.15-4.05 ppm, s. 3H 3.79 ppm; s. 3H 2.93 ppm; s. 3H 1.98 ppm; s. 3H 1.83 ppm.

1-Ethyl-3-phenyl-5-[3-methoxy-4-(2-acetamido-3,4,6-tris-O-acetyl-2-desoxy- $\alpha$-D-glycopyranosyloxy)phenyl]-7,8-dimethoxypyrazolo[3,4-c] isoquinoline (7), yield $49 \%$; m.p. $230^{\circ} \mathrm{C},[\alpha]_{546}-0,03^{\circ}$ (c 1,0 ; chloroform). ${ }^{1} \mathrm{H}$ NMR: d. $2 \mathrm{H} 8.35$ ppm J=8.0 Hz; d. 1H 8.14 ppm, J=9.1; Hz, s. $1 \mathrm{H} 7.66$ ppm; s. $1 \mathrm{H} 7.57$ ppm, dd 2H 7.54 J=8.0 Hz, J=7.3 Hz; ws. 1H 7.44 ppm; wd 1H 7.37 ppm, J=7.4 Hz; d. 1H 7.34 ppm, J=7.4 Hz; t 1H 7.30 ppm, J=7.3 Hz; d. 1H 5.49 ppm J=8.5 Hz, dd 1H 5.28 ppm J=9.5 J=10.0 Hz; dd 1H 4.97 ppm J=9.5 J=9.5 Hz; m 1H 4.3-4.2 ppm; m 6H 4.15-4.00 ppm, s. 3H 3.83 ppm; s. 3H 3.80 ppm; s. 3H 1.98 ppm; s. 3H 1.82 ppm; t 3H $1.50 \mathrm{ppm} 7.4 \mathrm{~Hz}$.

1-Ethyl-3-phenyl-5-[4-(2-acetamido-3,4,6-tris-O-acetyl-2-desoxy- $\alpha$-D-glycopyranosyloxy)phenyl]-7,8-

dimethoxypyrazolo[3,4-c]isoquinoline (8), yield $60 \%$; m.p. $269^{\circ} \mathrm{C}$, $[\alpha]_{546}-0,04^{\circ}$ (c 1,0; chloroform). ${ }^{1} \mathrm{H}$ NMR: d. 2H 8.33 ppm J=8.3 Hz; d. 1H 8.17 ppm, J=9.0 Hz; d. 2H 7.80 ppm, J=8.2; s. 1H 7.66 ppm, dd 2H 7.54 ppm J=8.33 Hz, J=7.4 Hz; s 1H 7.52 ppm; t 1H 7.30 ppm, J=7.4 Hz; d. 2H, 7.24 ppm, J=8.2 Hz; d. 1H 5.52 ppm J=8.5 Hz, dd 1H 5.27 ppm J=9.7 J=10 Hz; dd 1H 4.97 ppm J=9.5 J=9.7 Hz; m 2H 4.3-4.28 ppm; m 5H 4.15-4.05 ppm, s. 3H 3.80 ppm; s. 3H 1.98 ppm; s. 3H 1.83 ppm; t 3H 1.51 ppm 7.4 Hz.

1-Methyl-3H-5-[4-(2-acetamido-3,4,6-tris-O-acetyl-2-desoxy- $\alpha$-D-glycopyranosyloxy)phenyl]-]-7,8-

dimethoxypyrazolo[3,4-c]isoquinoline (9), yield $42 \%$; m.p. $248^{\circ} \mathrm{C}$, $[\alpha]_{546}-0,04^{\circ}$ (c 1,0; chloroform). ${ }^{1} \mathrm{H}$ NMR: s. 1H 13.29 ppm; d. 1H 8.16 ppm, J=9.2 Hz; d. 2H 7.71 ppm, J=8.40 Hz; s. 1H 7.67 ppm, s $1 \mathrm{H} 7.46$ ppm; d. 2H, 7.21 ppm, J=8.40 Hz; d. 1H 5.50 ppm J=8.5 Hz, dd 1H 5.26 ppm J=9.8 J=10.8 Hz; dd 1H 4.97 ppm J=9.5 J=9.4 Hz; m 2H 4.30-4.15 ppm; m 5H 4.15-4.00 ppm, s. 3H 3.76 ppm; s. 3H 2.82 ppm; s. 3H 1.97 ppm; s. 3H 1.83 ppm.

1,5-Dimethyl-3-(2-acetamido-3,4,6-tris-O-acetyl-2-desoxy- $\alpha$-D-glycopyranosyloxy)-7,8-dimethoxypyrazolo[3,4-c]isoquinoline (11).

To a solution of isoquinoline $\mathbf{1 0}(1.2 \mathrm{mmol})$ and $\alpha$-chloride $\mathbf{1}(1.2 \mathrm{mmol})$ in $10 \mathrm{ml}$ of anhydrous toluene was added mercury(II)bromide $(1.31 \mathrm{mmol})$. The reaction mixture heated to reflux to full convertion of glycosyl-donor (TLC control). The solid phase was filtered off, washed by toluene $(2 \times 5 \mathrm{ml})$ solvent was evaporated in vacuo. The residue was purified by column chromatography [silica gel, $\mathrm{CHCl}_{3} / \mathrm{iPrOH}(100: 1) \rightarrow \mathrm{CHCl}_{3} / \mathrm{iPrOH}$ (30:1), to give target product 11. Yield $18 \%$; m.p. $273-275^{\circ} \mathrm{C}$, $[\alpha]_{546}-25^{\circ}$ (c 1,0; chloroform). ${ }^{1} \mathrm{H}$ NMR: d. $1 \mathrm{H} 8.00 \mathrm{ppm}$, J=8.5 Hz; s. 1H 7.56 ppm; s. 1H 7.55 ppm; wd. 1H 6.50 ppm J=8.5 Hz; dd 1H 5.53 ppm J=9.6 J=9.6 Hz; dd 1H 5.04 ppm J=9.6 J=9.8 Hz; wm 1H 4.7-4.9 ppm; m 2H 4.3-4.1 ppm, s. 3H 4.18 ppm; m. 1H 3.9-4.0; s. 3H 3.96 ppm; s. 3H 2.93 ppm; s. 3H 2.76 ppm; s. 3H 2.03 ppm; s. 3H 1.98 ppm; s. 3H 1.97 ppm; s. 3H 1.48 ppm. 


\section{References}

1. Kobrakov K., Malienko A., Sujkov S., Perepichka I. et al.: J. Heterocyclic Chemistry., 2001, 38, 523. https://doi.org/10.1002/jhet.5570380238

2. Kobrakov K., Malienko A., Perepichka I., Sujkov S. et al.: Org. Biomol. Chem., 2005, 3, 932. https://doi.org/10.1039/B417002D

3. Li Rongshi., Xue Liquan., Zhu Tong., Jiang Qin. et al.: J. Med. Chem., 2006, 49, 1006. https://doi.org/10.1021/jm050824x

4. Oncolytic drugs. Drug Data Report., 2007, 29, 644.

5. Anand N., Blazey C., Bowles O., Bussenius J. et al.: Pat. 7872014 US, Publ. 18.01.2011.

6. Kondratov R., Komarov P., Becker Y., Ewenson A., Gudkov A.V.: PNAS, 2001, 98, 14078 https://doi.org/10.1073/pnas.241314798

7. Gudkov A., Kondratov R.: Pat. 20030073611 US, Publ. 17.04.2003.

8. Nikolukin Yu., Zubrickii M., Dulenko V.: Jurnal Orhanicheskoi Khimii., 1993, 29,1480 (in Russian).

9. Zinchenko S., Efimenko R., Suikov S., Kobrakov K.: Chem. Heterocycl. Comp., 2009, 45, 365. https://doi.org/ 10.1007/s10593-009-0262-2.

10. Zhong H., Zou H., Semenov M., Moshinsky D. et al. Molecular BioSystems, 2009, 5, 1356. https://doi.org/10.1039/B905752H.

11. Teller S., Eluwa S., Koller M., Uecker A. et al.: Eur. J. Med. Chem., 2000, 35, 413. https://doi.org/10.1016/S0223-5234(00)00140-9.

12. Coghlan R., Fobare W., Trybulski E.: Pat. 0154875 US, Publ. 13.07.2006.

13. Wong N., Forgione P.: Org. Lett., 2012, 14, 2738. https://doi.org/10.1021/ol3009655

14. Kur'yanov V., Chupakhina T., Zemlyakov A., Kotlyar S. et al. Rus. J. Bioorg. Chem., 2001, 27, 385. https://doi.org/10.1023/A:1012988719296

15. Kur'yanov V., Priskoka U., Chupakhina T., Chirva V.: Rus. J. Bioorg. Chem., 2005, 31, 301-304. https://doi.org/10.1007/s11171-005-0042-4

16. Zinner H., Peseke C.: Chem. Ber., 1965, 98, 3508. https://doi.org/10.1002/cber.19650981110

17._Sujkov S.: Proceedings of scientific conference Structure of organic compounds and reaction mechanisms, Ukraine, Donetsk, 1999, 44. 